OPEN ACCESS

Edited by: Hansen Wang,

University of Toronto, Canada

Reviewed by:

Susanne Frykman,

Karolinska Institutet (KI), Sweden

Béatrice Schaack,

Commissariat à l'Energie Atomique et aux Energies Alternatives (CEA),

France

*Correspondence:

Francisco Wandosell fwandosel/@cbm.csic.es

Received: 14 January 2020 Accepted: 24 April 2020

Published: 25 May 2020

Citation: Ordóñez-Gutiérrez $L$ and Wandosell $F$ (2020) Nanoliposomes as a Therapeutic Tool for Alzheimer's Disease. Front. Synaptic Neurosci. 12:20. doi: 10.3389/fnsyn.2020.00020

\section{Nanoliposomes as a Therapeutic Tool for Alzheimer's Disease}

\author{
Lara Ordóñez-Gutiérrez ${ }^{1,2}$ and Francisco Wandosell ${ }^{1,2 *}$ \\ 'Department of Molecular Neurobiology, Centro de Biología Molecular "Severo Ochoa" (CSIC-UAM), Universidad Autónoma \\ Madrid, Madrid, Spain, ${ }^{2}$ Centro de Investigación Biomédica en Red de Enfermedades Neurodegenerativas (CIBERNED), \\ Madrid, Spain
}

The accumulation of extracellular amyloid-beta $(A \beta)$, denoted as senile plaques, and intracellular neurofibrillary tangles (formed by hyperphosphorylated Tau protein) in the brain are two major neuropathological hallmarks of Alzheimer's disease (AD). The current and most accepted hypothesis proposes that the oligomerization of $A \beta$ peptides triggers the polymerization and accumulation of amyloid, which leads to the senile plaques. Several strategies have been reported to target $A \beta$ oligomerization/polymerization. Since it is thought that $A \beta$ levels in the brain and peripheral blood maintain equilibrium, it has been hypothesized that enhancing peripheral clearance (by shifting this equilibrium towards the blood) might reduce $A \beta$ levels in the brain, known as the sink effect. This process has been reported to be effective, showing a reduction in $A \beta$ burden in the brain as a consequence of the peripheral reduction of $A \beta$ levels. Nanoparticles (NPs) may have difficulty crossing the blood-brain barrier (BBB), initially due to their size. It is not clear whether particles in the range of 50-100 nm should be able to cross the BBB without being specifically modified for it. Despite the size limitation of crossing the BBB, several NP derivatives may be proposed as therapeutic tools. The purpose of this review is to summarize some therapeutic approaches based on nanoliposomes using two complementary examples: First, unilamellar nanoliposomes containing $A \beta$ generic ligands, such as sphingolipids, gangliosides or curcumin, or some sphingolipid bound to the binding domain of ApoE; and second, nanoliposomes containing monoclonal antibodies against A $\beta$. Following similar rationale NPs of poly(lactide-co-glycolide)-poly (ethylene glycol) conjugated with curcumin-derivate (PLGA-PEG-B6/Cur) were reported to improve the spatial learning and memory capability of APP/PS1 mice, compared with native curcumin treatment. Also, some new nanostructures such as exosomes have been proposed as a putative therapeutic and prevention strategies of AD. Although the unquestionable interest of this issue is beyond the scope of this review article. The potential mechanisms and significance of nanoliposome therapies for AD, which are still are in clinical trials, will be discussed.

Keywords: neurodegeneration, Alzheimer therapy, immunotherapy, nanoparticle, liposomes, immunoliposomes 


\section{INTRODUCTION}

Currently, the treatment of Alzheimer's disease (AD) pathology is one of the most disappointing examples of exploration for new drugs in Biomedicine. Despite a great number of putative molecular targets described in the literature and significant positive data from animal models, there are only a few symptomatic treatments offered, with no cure yet available (Mangialasche et al., 2010; Schneider et al., 2014). The reasons for this can be attributed to numerous factors: (1) the lack of selectivity and specificity of anti-AD drugs; (2) the inability of most drugs to cross the blood-brain barrier (BBB); (3) the selection of only one target to test efficacy, since $A D$ has a multifactorial and complex etiopathology; or (4) the selection of patients in an advanced state of pathology. The recruitment of patients in very early stages of the disease was initially complex due to the lack of good, early diagnostic markers. This issue is now address using a combination of CSF biomarkers, blood biomarkers, MRI, Amyloid PET, Tau PET, et cetera (Bateman et al., 2012). These combinatory and additional approaches are being used to define common or differentiating biological denominators across the different neurodegenerative diseases to define stages of pathophysiological progression, characterize systems-based intermediate endophenotypes, and validate multi-modal novel diagnostic systems biomarkers. All these data will favor more robust clinical intervention trial designs (Hampel et al., 2018).

$\mathrm{AD}$ is the most common neurodegenerative disorder, and it is characterized by the presence of two pathological hallmarks in the brain: the deposition of extracellular amyloid plaques (senile plaques); and the formation of intracellular neurofibrillary tangles (Alzheimer et al., 1995). Amyloid plaques mainly contain the amyloid-beta $(A \beta)$ peptide, which is released by proteolytic cleavage of the amyloid precursor protein (APP; Selkoe, 2001; Hardy and Selkoe, 2002; Selkoe and Hardy, 2016). Indeed, $\mathrm{A} \beta$ peptides are generated by two consecutive proteases, $\beta$-secretase and $\gamma$-secretase, which leads to the production of different amyloid varieties such as $\mathrm{A} \beta 40, \mathrm{~A} \beta 42$ or $\mathrm{A} \beta 43$ (Iwatsubo et al., 1994; Haass and Selkoe, 2007; Olsson et al., 2014). In contrast, the intracellular neurofibrillary tangles are composed of the hyper-phosphorylated and polymerized Tau protein (for review see i.e., Hernandez and Avila, 2008). In addition to these histopathological hallmarks, a series of cellular events occur throughout the progression of the pathology in the brain parenchyma: microglia and astrocyte activation, synaptic dysfunction, axonal transport failure, and even neuronal death.

The most accepted hypothesis proposes that oligomerization of $\mathrm{A} \beta$ peptides trigger the polymerization and accumulation of amyloid, which generates the senile plaques. However many data strongly suggested that the oligomeric forms of $A \beta$ are probably the most toxic species. And several hypothesis support this toxic effect, such as the capacity to $A \beta$ and $\mathrm{A} \beta$-peptides to bind membrane components (Barrett et al., 2012), increasing dysfunction in ER and/or ROS and mitochondrial homeostasis, et cetera (Cheignon et al., 2018; Poirier et al., 2019; Ashkavand et al., 2020).
In parallel, several characterized neuronal dysfunctions trigger the hyper-phosphorylation and accumulation of Tau (Hardy and Selkoe, 2002).

Numerous strategies have been developed to target amyloid generation or accumulation, as well as Tau accumulation or hyper-phosphorylation. Also, many different compounds such as calcium or ROS modulators, glutamate receptor antagonists, cholinergic transmission modulators, cholinesterase inhibitors, some kinase inhibitors, etc., have been assayed in preclinical and clinical trials (for a review see i.e., Mangialasche et al., 2010; Schneider et al., 2014). Unfortunately, many candidate drugs have failed to show a clinical benefit in established, early, or prodromal disease, or in those with high AD risk, and the few symptomatic treatments are limited to the targeting of cholinergic deficits and glutamatergic dysfunction (Tayeb et al., 2012). Thus immunotherapy is or could be one complementary method that has been proposed for its ability to reduce the accumulation of $\mathrm{A} \beta$ and potentially treat the underlying cause of AD.

\section{HOW TO FIND NEW THERAPEUTIC ALTERNATIVES AGAINST ALZHEIMER'S DISEASE}

Strategies have been reported using several compounds against polymerization, as well as antibodies against different regions (Mangialasche et al., 2010) or different oligomerization states of the A $\beta$ peptide (Zhao et al., 2017). One such strategy is based on the hypothesis that there exists an equilibrium between the $\mathrm{A} \beta$ levels in the brain and the peripheral blood. Thus, it was postulated that if this equilibrium were altered by enhancing peripheral clearance, it would reduce $A \beta$ levels in the brain. Through this so-called "sink effect," it was shown that peripheral reduction of $A \beta$ levels provokes a reduction in $A \beta$ brain burden (Matsuoka et al., 2003; Biscaro et al., 2009). This initial hypothesis was further supported by the fact that immunotherapy facilitates clearance of $A \beta$ in animal models of $A D$ (DeMattos et al., 2001; Lemere et al., 2003; Sutcliffe et al., 2011). However the hypothesis is still a matter of discussion, while some data did not support this theory, for instance, some peripheral depletion of $A \beta$ does not affect central levels of $A \beta$ (Henderson et al., 2014). Even in our experiments the same preparation of inmunoliposomes, had no brain effect in the AD model, with adult mice, but it did with older mice (Ordóñez-Gutiérrez et al., 2017). Although in the case of aged mice, the nanoliposomes were more effective than the same amount of free IgG. This supports, at least in part, a hypothesis of peripheral effect more, or more powerful than the central one, which we cannot rule out.

Certainly, the mechanisms by which antibodies against $A \beta$ can clear brain $A \beta$ remains to be clarified. Translocation of antibodies across the $\mathrm{BBB}$, if it is even possible, is still a controversial issue. One of the main issues is whether the amount of antibodies crossing the $\mathrm{BBB}$ is sufficient to be therapeutically relevant. One possibility is that IgG translocation is modulated by the $\mathrm{BBB}$ at different disease stages; perhaps in some initial stages of $\mathrm{AD}$, the $\mathrm{BBB}$ is compromised to permit IgG's translocation. It 
is essential to address the ability of the immune system to clear the antibody-amyloid complexes without provoking excessive neuroinflammation.

However, the sink effect hypothesis proposes that a reduction of $A \beta$ in the peripheral plasma generates a concentration gradient across the $\mathrm{BBB}$, which promotes efflux of brain $\mathrm{A} \beta$ into the blood (DeMattos et al., 2001; Lemere et al., 2003). Alternatively, other groups have proposed that a "significant $\mathrm{A} \beta$ pool" may have been generated in the periphery and then transfers to the brain through the $\mathrm{BBB}$. Consequently, any strategy that reduces plasma $A \beta$ levels could effectively decrease $A \beta$ transportation and deposition in the brain, thereby minimizing plaque formation (Sutcliffe et al., 2011).

The first approach for immunotherapy was an in vitro assay that revealed that anti- $\mathrm{A} \beta$ antibodies greatly reduced fibrillary formation, disrupting pre-formed fibrils, and preventing neurotoxicity (Solomon et al., 1997). The initial data reported that full-length, aggregated $\mathrm{A} \beta 42$ with Freund's adjuvant could reduce plaque load in vivo, in an $\mathrm{AD}$ mouse model with no obvious toxicity (Schenk et al., 1999). Similarly, later studies using $A \beta 42$ or $A \beta$ homologous peptides with different adjuvants not only strongly reduced $A \beta$ plaques but also prevented cognitive deficits (Janus, 2003; Lemere et al., 2006; Morgan, 2006, 2011; Sigurdsson, 2008). These data suggest that an immune response is generated in the mouse against the amyloid peptide $A \beta 42$ that must be responsible for the therapeutic effect, whether the antibodies cross the BBB or not. However, it is important to note that the results obtained in mouse models are hardly reproducible in humans. Not in vain, to reproduce $\mathrm{AD}$ hallmarks in mouse models, it is necessary to express two (APP and Tau) or three (APP, Presenilin, and Tau) dominant mutations. And we have to remind that Tau mutations are not FAD mutations, but only found in FTD and other tauopathies, thus the mice model of triple mutations is genetically speaking, not a good AD model.

These experiments opened up the second strategy: peripheral injections of anti- $A \beta$ monoclonal antibodies (MAbs). Interestingly, peripheral injections of MAbs also reduced $A \beta$ plaque burden and behavior, with no evidence of toxicity in the immunized mice (Bard et al., 2000; DeMattos et al., 2001; Lemere, 2013; Wisniewski and Goñi, 2015). All these data strongly support the hypothesis that the therapeutic effect of the vaccine was likely mediated by the humoral response (Wisniewski and Goñi, 2014). The data from preclinical studies served to launch some phase I clinical trials (Bayer et al., 2005; Wisniewski and Frangione, 2005), wherein full-length A $\beta 42$ and different adjuvants were assayed. More than $50 \%$ of the healthy subjects generated an anti-A $\beta$ humoral response, in some cases with different Th-1/Th-2 lymphocyte responses (Pride et al., 2008). A complementary phase II trial was initiated in 2001, however, $6 \%$ of the immunized patients presented symptoms of aseptic meningoencephalitis, and the trial was terminated early in 2002 (Wisniewski and Frangione, 2005; Boche et al., 2010).

At present, several passive immunization trials are underway at either Phase I, II, or III, based on different fragments of $A \beta 1-42$ and/or different formulations ${ }^{1}$. However, several phase III trials (such as Bapineuzumab and Solanezumab) failed to show overall clinical improvement or any clear diseasemodifying results (Doody et al., 2014; Salloway et al., 2014a,b; Panza et al., 2019). Thus, immunotherapeutic approaches have thus far generated mixed therapeutic outcomes, more positive in animal $\mathrm{AD}$ models than in patients (for a more recent update see: Panza et al., 2019). These discrepancies may be due to species differences and considerations in age, disease stage and associated variations in BBB permeability, as well as adverse neuroinflammatory effects (Bard et al., 2000; DeMattos et al., 2001; Demattos et al., 2012; Orgogozo et al., 2003; Doody et al., 2014; Salloway et al., 2014a,b).

At present only a few immunotherapies in clinical trials II and III are still in progress (i.e., Aducanumab-BIIB037, or BAN2401; Logovinsky et al., 2016; Sevigny et al., 2016; Arndt et al., 2018). In the case of Aducanumab after two initial failed analyses of the phase $3 \mathrm{AD}$ trials, in 2019 they reanalyzed data the company showed some significant findings and a subset from the second trial supports these positive findings. In Oct 2019, the company did apply for the US Food and Drug Administration (FDA) marketing approval of Aducanumab.

After these initial unsuccessful attempts, different approaches have since been initiated, some of which are based on new antibodies targeting different regions of $A \beta$ (Boutajangout et al., 2019; Zhang et al., 2019), Tau (Sigurdsson, 2008, 2018) or BACE (Atwal et al., 2011), or stem from new formulations of antibody presentation (Hasegawa et al., 2010; Wong et al., 2019).

\section{NANOPARTICLES AS A NEW TOOL AGAINST NEURODEGENERATIVE DISEASES}

NPs are materials or devices on a scale between 1-100 nm, and represent an innovative and promising approach, mostly due to their physicochemical features and the possibility of multi-functionalization, allowing them to confer more than one feature at the same time, such as the ability to cross the BBB. Recently, nanomaterials have emerged as an alternative to deliver different drugs for several pathologies including cancer and brain diseases.

At present, several classes of NPs (i.e., solid lipid nanoparticles (SLN), PLA/PLGA NPs, dendrimers, nanofibers, nanotubes, nanoliposomes, nanogels) are available for preclinical or biomedical use with different physicochemical features and applications (see some schematic representation in Figure 1).

In the field of Nanomedicine, the "pros and cons" of this variety of NPs are still being defined. One of the common advantages of the NP is the possibility of multifunctionalization, coupled to their ability to carry drug cargos, included BBB-impermeant drugs. In particular, for brain drug delivery is that proper surface multifunctionalization may promote at the same time either their targeting of the $\mathrm{BBB}$ or the enhancement of its crossing. This would be the case of, for instance, Liposomes, SLN, Polymeric, and Non-polymeric NPs. All these would have

\footnotetext{
${ }^{1}$ http://www.clinicaltrials.gov
} 


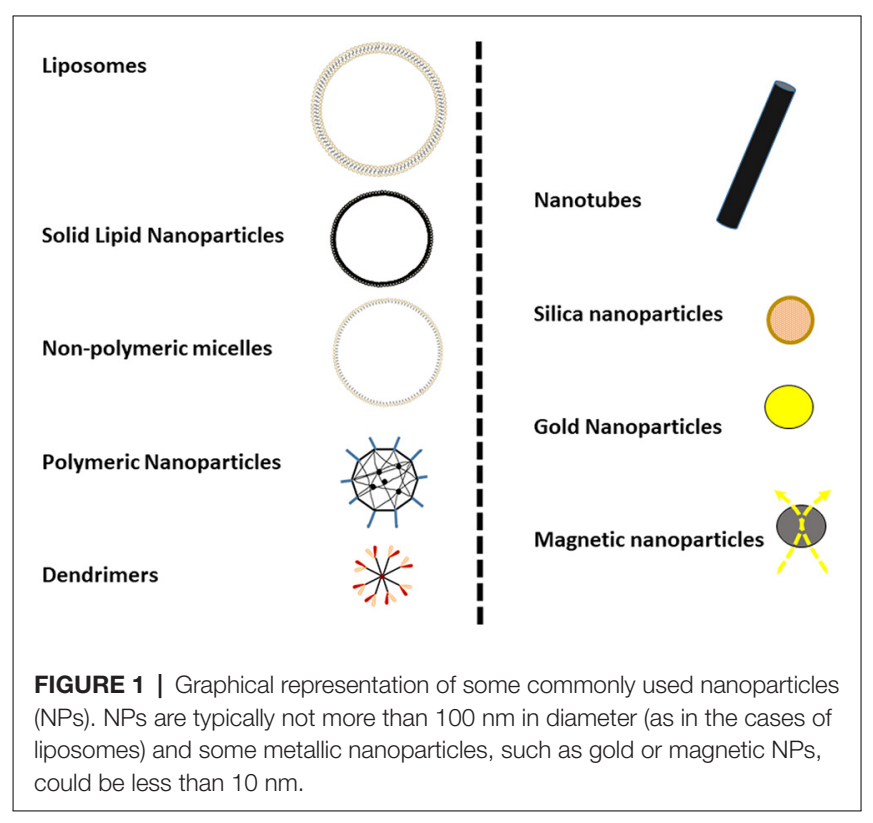

some surface multifunctionalization and carrying drug cargo (hydrophilic and hydrophobic pharmaceuticals). In contrast, the size or the size after multifunctionalization would be the negative aspect.

Some of them have been used in preclinical models for neurodegenerative diseases, however specific nanoliposomes, such as Doxorubicin Liposomal (Doxil ${ }^{\circledR}$ ) are available for cancer therapy, alone (Su et al., 2015; Gong et al., 2016; Shi et al., 2017) or in combination (i.e: Monk et al., 2020).

A second group, in which they would be Nanotubes or Silica, Gold, Iron (magnetic or not) NPs, have in its favor the production in small sizes, their high chemical, and biological stability or some specific properties, such the capacity to be heated (magnetic particles; Wu et al., 2019). These NPs have the advantage of being very small and homogeneous but of greater difficulty to modify and derivatize their surface. However, most of these NPs group have not been derivatized or not used in Neurodegeneration models, so far. Only magnetic iron NPs are having a broader development in cancer treatments ( $\mathrm{Wu}$ et al., 2019).

Moreover, many NPs can be functionalized by covalent conjugation to various ligands (such as antibodies, proteins, or aptamers) to target specific tissues. Another important consideration is the biocompatibility, in the group of Liposomes, SLN, Polymeric, and Non-polymeric NPs and dendrimers, many of these backbones could be easily metabolized, with low toxicity. However, in the case of metal derived NPs a more exhaustive pharmacokinetic analysis has to be done.

In the field of neurodegeneration, NPs are an interesting biomedical tool with the potential to solve different problems. At a therapeutic level, they offer the possibility of being multifunctionalized; for example, one ligand may enable the crossing of the BBB to deliver a second ligand, the drug. They may also have uses in the diagnostic field, where one ligand may enhance the capacity to bind amyloid plaques, whereas the second would facilitate "molecular imaging" techniques (Mori et al., 2012; Bao et al., 2013; Liu et al., 2016).

At present, a plethora of different NPs have been assayed in cellular and animal models, and in many cases are already in the initial stages of a preclinical study in models of $\mathrm{AD}$ (i.e., Ordóñez-Gutiérrez et al., 2015, 2017; Sanchez-Lopez et al., 2017; Carradori et al., 2018). The field of nanotechnology devoted to therapeutic purpose is growing exponentially, with many broad or more specialized reviews having been published recently (i.e., Karthivashan et al., 2018; Aliev et al., 2019; Formicola et al., 2019).

Some of these NPs have had very little development, for example, micellar nanocarriers, and only some of them have been tested in $\mathrm{AD}$ models (Singh et al., 2018). In contrast, more data is available on the use of Dendrimers as a class of well-defined branched polymers that are chemically synthesized with a well-defined shape, a size that could be used not only for site-specific medications but for MRI diagnosis and gene therapy. For example, some initial reports indicated that gallic acid-triethylene glycol (GATA) dendrimers reduced amyloid toxicity (Klajnert et al., 2012). More recently polyamidoamine (PAMAM) and polypropyleneimine (PPI) dendrimers nanomacromolecules have received more attention as candidates for the treatment of neurodegenerative diseases (Aliev et al., 2019).

Nevertheless, in this review, we will focus only on liposomebased therapy.

\section{LIPOSOME-BASED THERAPY AGAINST A $\beta$ PLAQUES}

Liposomes are a biocompatible, highly flexible drug delivery system, with the potential to carry many different types of bioactive molecules, both on the inside and/or outside of the particle. Their biochemical composition and formulation facilitate numerous modifications. We can consider two options: First, a non-targeted liposome, which can transport the compound directly; and second, "targeted" liposomes which are designed to interact with specific molecular targets relevant to the diagnosis, treatment, or prevention of $\mathrm{AD}$. Regardless, liposomes can incorporate hydrophilic (entrapped in the aqueous core) or hydrophobic compounds (contained within the lipid bilayer). Indeed, incorporation of multiple compounds can grant therapeutic activity while also facilitating the passage of the $\mathrm{BBB}$ (Mancini et al., 2016, 2017; Vieira and Gamarra, 2016; Dal Magro et al., 2017), as recently reported using two ligands: one external ligand to favor BBB entry and another with therapeutic potential (Balducci et al., 2014).

\section{LIPOSOME LIGANDS AGAINST A $\beta$ : COMPOUNDS/DRUGS VS. ANTIBODIES}

In vivo assays using $\mathrm{AD}$ animal models have been used to follow different strategies, either using synthetic or natural compounds with previously reported affinity for $A \beta$ peptides, such as curcumin-derivatives (Thioflavin-T), anionic phospholipids (gangliosides), or antibodies against specific $A \beta$ regions. In 
many cases, we have direct information about how these compounds may affect $\mathrm{AD}$ hallmarks. However, there is not much comparative data regarding whether some of these compounds are more effective when administered alone or in a NP-bound form. In the next section, we will summarize some of these comparative data.

\section{Molecules That Might Bind A $\beta$}

Curcumin is a naturally occurring phytochemical phenol and is a potent antioxidant and anti-inflammatory compound. It is known that curcumin targets $A \beta$, interferes with amyloid polymerization, amyloid plaque formation, and amyloid toxicity directly (Kim et al., 2001; Yang et al., 2005), and indirectly enhance $A \beta$ clearance (Zhang et al., 2006; Begum et al., 2008), suggesting a potential role for prevention or treatment of $\mathrm{AD}$. Curcumin derivatives have been used including curcumindecorated nanoliposomes, as liposomes exposing the curcumin derivative have an extremely high affinity for $A \beta 42$ fibrils (Mourtas et al., 2011). More recently, NPs of poly(lactide-coglycolide)-poly (ethylene glycol) conjugated with curcuminderivate (PLGA-PEG-B6/Cur) were reported to improve the spatial learning and memory capability of APP/PS1 mice, compared with native curcumin treatment. This report indicated that PLGA-PEG-B6/Cur could reduce hippocampal A $\beta$ formation/deposit and Tau hyperphosphorylation. Thus, they suggested that NPs conjugated with curcumin derivatives could hold promise as a drug for the treatment of $\mathrm{AD}$ (Fan et al., 2018).

Similarly, several groups (including ours) have demonstrated that liposomes containing phosphatidic acid (PA) and cardiolipin (CL) reduce $\mathrm{A} \beta$ levels in APP/PS1 transgenic mice. This data came from a European consortium, part of the Seventh Framework Programme (FP7/2007-2013; NAD: NPs for Therapy and Diagnosis of Alzheimer Disease ${ }^{2}$ ), devoted to the analysis of NPs to treat $\mathrm{AD}$. The initial data showed that functionalized liposomes with PA and CL still maintain the ability to bind A $\beta 42$ (Balducci et al., 2010). Then, we tested whether intraperitoneal injection of small unilamellar liposomes containing either PA or CL could reduce the amyloid burden in APP/PS1 transgenic mice. We observed that this treatment significantly reduced the amount of $A \beta$ in the plasma, with only a tendency to decrease $A \beta$ levels in the brain. Nevertheless, this dosing regimen did modulate Tau phosphorylation and glycogen synthase kinase 3 activities in the brain, suggesting that the targeting of circulating $A \beta$ may be therapeutically relevant in AD. In contrast, treatment with plain liposomes was devoid of any effect (Ordóñez-Gutiérrez et al., 2015).

We initially considered that these unilamellar liposomes were not able to cross the $\mathrm{BBB}$ even though we detected neuronal changes in the $\mathrm{AD}$ mouse model, suggesting some biochemical connection between the putative effect on the periphery with changes inside the central nervous system (CNS), as inferred from the modification in the phosphorylation levels of neuronal-specific proteins (Ordóñez-Gutiérrez et al., 2015). Thus, the next approach was to test bifunctionalized

\footnotetext{
${ }^{2}$ http://www.nadproject.eu/
}

liposomes (mApoE-PA-Lipo), with ApoE-peptides to improve BBB passage (Arsenault et al., 2011). This report indicated that the uptake of nanoliposomes by cell monolayers was enhanced by containing acidic phospholipids with the ApoE-peptide-functionalization, and was higher with the 141-150aa fragment than with its tandem dimer. Intraperitoneal injection of mApoE-PA-Lipo for 3 weeks (three injections per week) showed a decrease in brain-insoluble $A \beta 1-42$ and in the area occupied by plaques, as detected histologically. Plaque reduction was confirmed in APP23 transgenic mice (15 months-of-age) either histologically or by PET imaging with $\left[{ }^{11} \mathrm{C}\right]$ Pittsburgh compound B (PIB). Also, the novel object recognition test showed that the treatment ameliorated the mice's impaired memory.

These data suggest that bifunctionalized liposomes destabilize brain $A \beta$ aggregates and promote peptide removal across the $B B B$ and its peripheral clearance (Balducci et al., 2014; Bana et al., 2014). All these data strongly support the idea that a similar multi-functionalized therapeutic device can be considered as a candidate for the treatment of AD (Formicola et al., 2019).

\section{Antibodies Against A $\beta$}

All these data open the next question: can a high-affinity ligand, such as an antibody, be an optimal therapeutic option after binding to NPs? As indicated above, different strategies for treatment and prevention of $\mathrm{AD}$ are currently under investigation, including passive immunization with anti- $\mathrm{A} \beta$ MAbs. Even though few of them remain in clinical trials (Panza et al., 2014, 2019), some have been assayed using different adjuvants, suggesting that the final in vivo inoculation may be essential for a therapeutic effect, even though it is generally accepted that a better set of biomarkers is essential to recruit and to follow patients in clinical trials.

However, the manipulation of specifically engineered nanomedicines to cross the BBB and target the selected "site of action" (i.e., $A \beta$, Tau, glial activation, inflammatory response, etc.), is one of the most interesting innovations in drug delivery. This could represent a promising choice for treatment or even early diagnosis of AD (Dal Magro et al., 2017; Song et al., 2018). In many cases, we did not have a comparative analysis showing whether a specific MAb used in AD models is more effective alone or in NP-bound form. Thus, a comparative analysis was performed to determine whether a new specific MAb against $A \beta 1-42$ would be more effective when free or when bound to nanoliposomes.

The MAb was generated in mice by immunization with $A \beta$ and after purification and characterization, a high affinity for both $\mathrm{A} \beta$ monomers and fibrils ( 0.08 and $0.13 \mathrm{~nm}$, respectively) was confirmed. After biotinylation and binding to the liposome, the affinity was lower, although still in the low nanomolar range (2.1 and $1.6 \mathrm{nM}$ for $\mathrm{A} \beta$ monomers and fibrils, respectively). Control IgG-decorated liposomes were generated by the same methodology (Canovi et al., 2011). Interestingly, only the A $\beta$ MAb-liposomes markedly bound to $\mathrm{A} \beta$ monomers and fibrils, and in this conformation, the affinity was determined around 0.5 and $2 \mathrm{nM}$ (for liposomes with high and low $\mathrm{A} \beta-\mathrm{MAb}$ density, respectively). The ability of $A \beta$-MAb-liposomes to bind 
to $A \beta$ fibrils was additionally confirmed by an ultracentrifugation technique, in which interactions occur in solution under physiological conditions (Canovi et al., 2011). This type of A $\beta$-MAb-liposome may be additionally modified without a major reduction of its affinity (Markoutsa et al., 2012), confirming the potential of these NPs for the diagnosis and therapy of AD.

Using a similar batch of A $\beta$-MAb-pegylated-liposome, we have performed two trials in different aged mice (adult and old), injecting APP/PS1 transgenic mice intraperitoneally. Our rationale was that in an "old mouse" AD model, perhaps the $\mathrm{BBB}$ is compromised and the percentage of nanoliposomes able to cross could increase. Thus, first, we tested in 10-month-old (adult) mice divided into four treatment groups ( $\mathrm{A} \beta$-MAb-liposome, plain-liposome, $\mathrm{A} \beta$-MAb alone, and control-IgG1 MAb) and intraperitoneally injected for 4 months. In the second assay, 16-month-old (elderly) mice were divided into three treatment groups (A $\beta$-MAb-liposome, $A \beta-M A b$, and control-IgG1 $\mathrm{MAb}$ ) and treated for 6 months by the same route of administration. In all cases, $4 \mathrm{mg}$ of liposomes and $150 \mu \mathrm{g}$ of antibody were given every 3 weeks (Ordóñez-Gutiérrez et al., 2017). This version of immunoliposomes dramatically reduced circulating and brain levels of Aß1-40, and particularly Aß1-42, in "elderly" but not "adult" APP/PS1 transgenic mice upon repeated intraperitoneal administration. A detailed analysis of the treated brains showed that the immunePEG liposome-mediated reduction in amyloidosis correlated with lower levels of glial fibrillary acidic protein (GFAP) and reactive glia (GFAP-positive cells). This treatment also lowered the ratio of phosphorylated Tau to total Tau. Thus, the therapeutic efficacy of immunoliposome treatment was age-dependent and superior to free MAb administration (at an equivalent antibody dose; Ordóñez-Gutiérrez et al., 2017; see the schematic representation in Figure 2).

In summary, as a proof-of-concept, the use of NPs conjugated with one or more ligands opens a new field of therapeutic approaches to neurodegenerative diseases, for several reasons. They can be multi-functionalized, able to cross BBB and they can be more effective than a similar amount of drug alone.

\section{TAU TARGETING AND OTHER RELATED THERAPIES}

As the second important hallmark of $\mathrm{AD}$, it is important to develop specific therapies directed at Tau. Although the pathophysiology of Tau-mediated neurodegeneration is not completely clear, Tau hyper-phosphorylation, oligomerization, and polymerization have been proposed as the likely pathological processes causing neurodegeneration (Yoshiyama et al., 2013). Thus, different therapeutic approaches have been proposed, some of which have been deeply studied in several assays (Novak et al., 2018a).

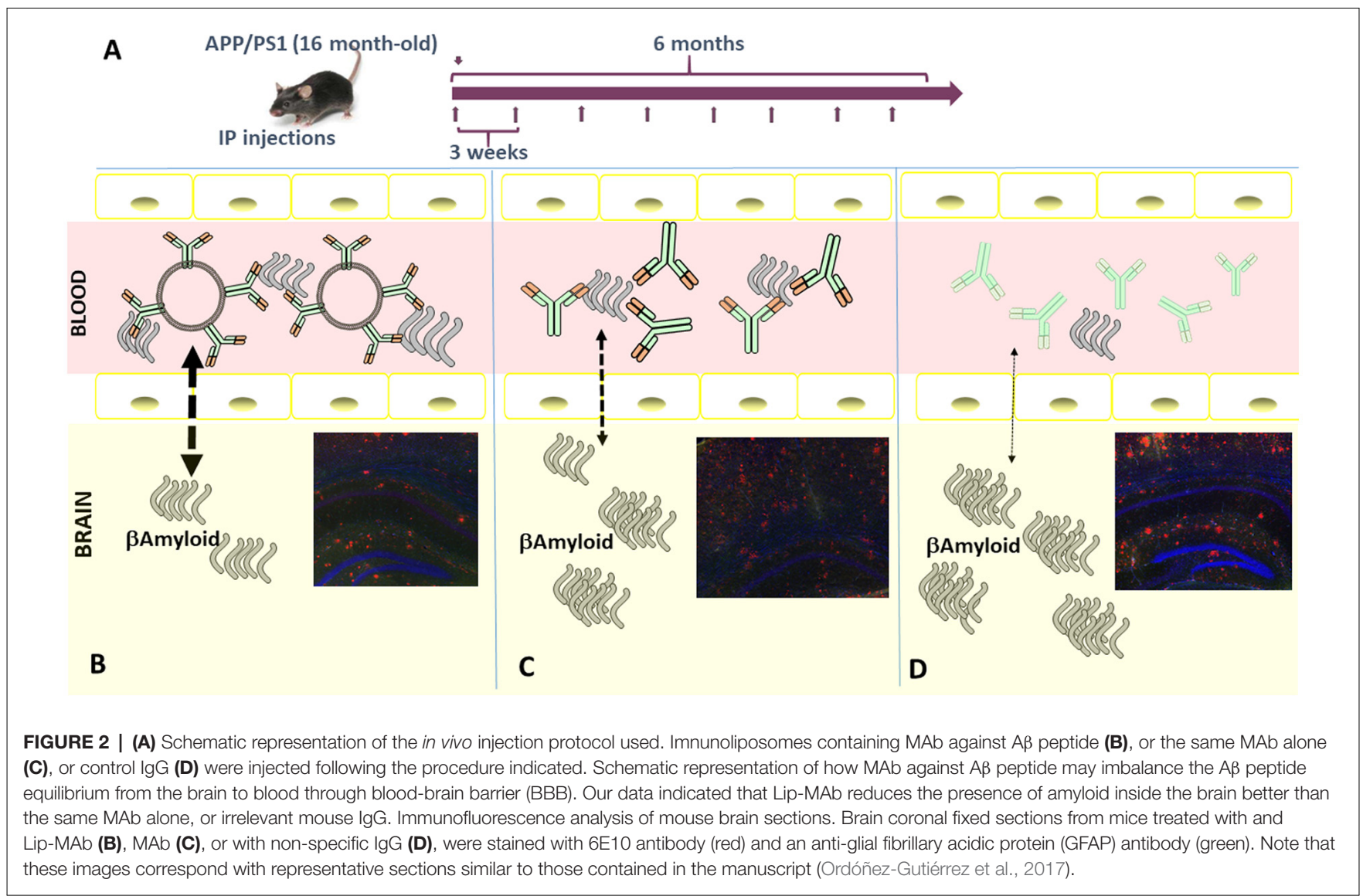


In initial Tau immunotherapy programs, it was reported that various active and passive Tau immunizations diminished pathology and improved brain functions (including cognition) in different mouse models. Both extra- and intracellular pathways were likely involved (Sigurdsson, 2014). It was proposed that some antibodies may block the spread of Tau pathology via microglial phagocytosis of the antibody-Tau complex and facilitate lysosomal Tau clearance in neurons after endosomal uptake (Sigurdsson, 2016, 2018).

Indeed, some years later, an active immunotherapy Tau-based strategy reached Phase II. This Tau peptide vaccine produced an important reduction in the levels of hyper-phosphorylated Tau and neurofibrils by approximately 95\% (Kontsekova et al., 2014). An adapted liposome-based amyloid vaccine was incorporated, using a synthetic phosphorylated peptide to mimic a phosphor-epitope of Tau protein. Long-term vaccination improved symptoms and reduced Tauophaty in P301L mice and this project is in Phase I (Theunis et al., 2013). And more recently AADvac1 tau vaccination trial reached Phase II (Novak et al., 2018b).

Alternatively, some authors have proposed a different approach to inhibit $A \beta$ production via antibodies against $\beta$-secretase (BACE), as $A \beta$ is produced in a two-step proteolytic process of APP, initiated by BACE1 and followed by $\gamma$-secretase. Due to its apparent rate-limiting function, BACE1 appears to be a prime target to prevent $A \beta$ generation in $A D$.

Two different approaches have been reported, using antibodies against the $\beta$-secretase cleavage site of the amyloid precursor protein. Some data indicates that these antibodies reduce endogenous $B A C E 1$ activity and $A \beta$ production in human cell lines expressing APP and in cultured primary neurons. And more importantly, long-term systemic administration of anti-APP beta-site antibodies to Tg2576 transgenic mice improved mouse cognitive functions associated with a reduction in both brain inflammation and the incidence of microhemorrhage (Rakover et al., 2007). The second alternative involves the direct targeting of BACE 1 since systemic dosing of mice and nonhuman primates with anti-BACE1 resulted in sustained reductions in peripheral $\mathrm{A} \beta$ peptide concentrations. Anti-BACE1 has been reported to be highly selective and does not inhibit the related enzymes BACE2 or cathepsin D. Thus, BACE1 can be targeted in a highly selective manner through passive immunization with anti-BACE1, providing another potential approach for treating AD (Atwal et al., 2011). Thus, therapeutic success with anti-BACE1 may depend on improving antibody uptake into the brain or being multi-functionalized in NPs.

The field of nanotechnology applied to neurodegeneration is expanding rapidly, and new materials and applications should be extensively analyzed. For example, some studies suggest that neuron-derived exosomes may participate in $\mathrm{A} \beta$ clearance in the brains. These authors described that neuronal exosomes, a subtype of extracellular nanovesicles, enwrap, or trap $A ß$ and transport it into microglia for degradation. They support the hypothesis that the pathway of $A B$ clearance by the exosomes may have potential significance as a novel therapeutic and prevention strategies of $\mathrm{AD}$. As a new nanotherapy, it should be carefully analyzed (Yuyama and Igarashi, 2017). Although of unquestionable interest, this issue is beyond the scope of this review.

\section{CONCLUSIONS}

The search for effective therapies against $\mathrm{AD}$ is at an important crossroads. A significant number of compounds with different targets have been tested and discarded. A series of challenges loom, foremost among them being the selection of patients; it is essential to find a group of molecular markers that facilitate diagnosis of pathology in prodromal phases. A set of markers that correctly distinguish Mild Cognitive Impairment (MCI) from pre-AD is needed for clinical trials, and given that this pathology can start 15-20 years before symptoms appear, this is a monumental task.

Secondly, new therapeutic targets must be found or reformulated to ensure the passage of the BBB. For this goal, the use of NPs seems quite promising, although more work needs to be done in animal models to confirm the improvement of this multifunctional formulation over the administration of the compound alone.

\section{AUTHOR CONTRIBUTIONS}

LO-G is the supervisor of our data and collaborations from the APP/PS1 mice model in our group. LO-G and FW accumulated the data and wrote the present review.

\section{FUNDING}

The research leading to these results was in part funded by the European Community's Seventh Framework Programme (FP7/2007-2013) under grant agreement $\mathrm{n}^{\circ} 212043$, grant EU FP7-2009-CT222887. In addition, the FW's lab was supported in part by grants from the Ministerio de Economía, Industria y Competitividad, Gobierno de España (MINECO)/FEDER SAF2015-70368-R, I+D+i-RETOS-RTI2018-096303-B-C1, CAM (B2017/BMD-3700), Centro de Investigación Biomédica en Red sobre Enfermedades Neurodegenerativas (CIBERNED); and by an institutional grant from the Fundación Ramón Areces to CBMSO and Fondos FEDER. LO-G has a Postdoctoral Contract from Centro de Investigación Biomédica en Red sobre Enfermedades Neurodegenerativas (CIBERNED).

\section{ACKNOWLEDGMENTS}

We thank the animal and microscopy facilities of Centro de Biologia Molecular Severo Ochoa CSIC-UAM for their technical support. Also, we thank all members of FW's lab for their support, help, and thoughtful discussions during the preparation of this manuscript. The professional editing service NB Revisions was used for the technical preparation of the text before submission. 


\section{REFERENCES}

Aliev, G., Ashraf, G. M., Tarasov, V. V., Chubarev, V. N., Leszek, J., Gasiorowski, K., et al. (2019). Alzheimer's disease-future therapy based on dendrimers. Curr. Neuropharmacol. 17, 288-294. doi: 10.2174/1570159X 16666180918164623

Alzheimer, A., Stelzmann, R. A., Schnitzlein, H. N., and Murtagh, F. R. (1995). An English translation of Alzheimer's 1907 paper, "Uber eine eigenartige Erkankung der Hirnrinde”. Clin. Anat. 8, 429-431. doi: 10.1002/ca.980080612

Arndt, J. W., Qian, F., Smith, B. A., Quan, C., Kilambi, K. P., Bush, M. W., et al. (2018). Immunotherapy with aducanumab restores calcium homeostasis in Tg2576 mice. Sci. Rep. 8:6412. doi: 10.1038/s41598-018-24501-0

Arsenault, D., Julien, C., Tremblay, C., and Calon, F. (2011). DHA improves cognition and prevents dysfunction of entorhinal cortex neurons in 3xTg-AD mice. PLoS One 6:e17397. doi: 10.1371/journal.pone.0017397

Ashkavand, Z., Sarasija, S., Ryan, K. C., Laboy, J. T., and Norman, K. R. (2020). Corrupted ER-mitochondrial calcium homeostasis promotes the collapse of proteostasis. Aging Cell 19:e13065. doi: 10.1111/acel.13065

Atwal, J. K., Chen, Y., Chiu, C., Mortensen, D. L., Meilandt, W. J., Liu, Y., et al. (2011). A therapeutic antibody targeting BACE1 inhibits amyloid- $\beta$ production in vivo. Sci. Transl. Med. 3:84ra43. doi: 10.1126/scitranslmed.3002254

Balducci, C., Beeg, M., Stravalaci, M., Bastone, A., Sclip, A., Biasini, E., et al. (2010). Synthetic amyloid- $\beta$ oligomers impair long-term memory independently of cellular prion protein. Proc. Natl. Acad. Sci. U S A 107, 2295-2300. doi: 10.1073/pnas.0911829107

Balducci, C., Mancini, S., Minniti, S., La Vitola, P., Zotti, M., Sancini, G., et al. (2014). Multifunctional liposomes reduce brain $\beta$-amyloid burden and ameliorate memory impairment in Alzheimer's disease mouse models. J. Neurosci. 34, 14022-14031. doi: 10.1523/JNEUROSCI.0284-14.2014

Bana, L., Minniti, S., Salvati, E., Sesana, S., Zambelli, V., Cagnotto, A., et al. (2014). Liposomes bi-functionalized with phosphatidic acid and an ApoE-derived peptide affect $A \beta$ aggregation features and cross the blood-brain-barrier: implications for therapy of Alzheimer disease. Nanomedicine 10, 1583-1590. doi: 10.1016/j.nano.2013.12.001

Bao, G., Mitragotri, S., and Tong, S. (2013). Multifunctional nanoparticles for drug delivery and molecular imaging. Annu. Rev. Biomed. Eng. 15, 253-282. doi: 10.1146/annurev-bioeng-071812-152409

Bard, F., Cannon, C., Barbour, R., Burke, R. L., Games, D., Grajeda, H., et al. (2000). Peripherally administered antibodies against amyloid $\beta$-peptide enter the central nervous system and reduce pathology in a mouse model of Alzheimer disease. Nat. Med. 6, 916-919. doi: 10.1038/78682

Barrett, J. P., Song, Y., Van Horn, W. D., Hustedt, E. J., Schafer, J. M., Hadziselimovic, A., et al. (2012). The amyloid precursor protein has a flexible transmembrane domain and binds cholesterol. Science 336, 1168-1171. doi: 10.1126/science. 1219988

Bateman, R. J., Xiong, C., Benzinger, T. L., Fagan, A. M., Goate, A., Fox, N. C., et al. (2012). Clinical and biomarker changes in dominantly inherited Alzheimer's disease. N. Engl. J. Med. 367, 795-804. doi: 10.1056/NEJMoa1202753

Bayer, A. J., Bullock, R., Jones, R. W., Wilkinson, D., Paterson, K. R., Jenkins, L., et al. (2005). Evaluation of the safety and immunogenicity of synthetic A $\beta 42$ (AN1792) in patients with AD. Neurology 64, 94-101. doi: 10.1212/01.wnl. 0000148604.77591 .67

Begum, A. N., Jones, M. R., Lim, G. P., Morihara, T., Kim, P., Heath, D. D., et al. (2008). Curcumin structure-function, bioavailability, and efficacy in models of neuroinflammation and Alzheimer's disease. J. Pharmacol. Exp. Ther. 326, 196-208. doi: 10.1124/jpet.108.137455

Biscaro, B., Lindvall, O., Hock, C., Ekdahl, C. T., and Nitsch, R. M. (2009). A $\beta$ immunotherapy protects morphology and survival of adult-born neurons in doubly transgenic APP/PS1 mice. J. Neurosci. 29, 14108-14119. doi: 10.1523/JNEUROSCI.2055-09.2009

Boche, D., Denham, N., Holmes, C., and Nicoll, J. A. (2010). Neuropathology after active A 342 immunotherapy: implications for Alzheimer's disease pathogenesis. Acta Neuropathol. 120, 369-384. doi: 10.1007/s00401-0100719-5

Boutajangout, A., Lindberg, H., Awwad, A., Paul, A., Baitalmal, R., Almokyad, I., et al. (2019). Affibody-mediated sequestration of amyloid $\beta$ demonstrates preventive efficacy in a transgenic Alzheimer's disease mouse model. Front. Aging Neurosci. 11:64. doi: 10.3389/fnagi.2019.00064
Canovi, M., Markoutsa, E., Lazar, A. N., Pampalakis, G., Clemente, C., Re, F., et al. (2011). The binding affinity of anti-A $\beta 1-42$ MAb-decorated nanoliposomes to $A \beta 1-42$ peptides in vitro and to amyloid deposits in post-mortem tissue. Biomaterials 32, 5489-5497. doi: 10.1016/j.biomaterials.2011. 04.020

Carradori, D., Balducci, C., Re, F., Brambilla, D., Le Droumaguet, B., Flores, O., et al. (2018). Antibody-functionalized polymer nanoparticle leading to memory recovery in Alzheimer's disease-like transgenic mouse model. Nanomedicine 14, 609-618. doi: 10.1016/j.nano.2017.12.006

Cheignon, C., Tomas, M., Bonnefont-Rousselot, D., Faller, P., Hureau, C., and Collin, F. (2018). Oxidative stress and the amyloid $\beta$ peptide in Alzheimer's disease. Redox Biol. 14, 450-464. doi: 10.1016/j.redox.2017.10.014

Dal Magro, R., Ornaghi, F., Cambianica, I., Beretta, S., Re, F., Musicanti, C., et al. (2017). ApoE-modified solid lipid nanoparticles: a feasible strategy to cross the blood-brain barrier. J. Control. Release 249, 103-110. doi: 10.1016/j.jconrel. 2017.01.039

Demattos, R. B., Lu, J., Tang, Y., Racke, M. M., Delong, C. A., Tzaferis, J. A., et al. (2012). A plaque-specific antibody clears existing $\beta$-amyloid plaques in Alzheimer's disease mice. Neuron 76, 908-920. doi: 10.1016/j.neuron.2012. 10.029

DeMattos, R. B., Bales, K. R., Cummins, D. J., Dodart, J. C., Paul, S. M., and Holtzman, D. M. (2001). Peripheral anti-A $\beta$ antibody alters CNS and plasma A $\beta$ clearance and decreases brain A $\beta$ burden in a mouse model of Alzheimer's disease. Proc. Natl. Acad. Sci. U S A 98, 8850-8855. doi: 10.1073/pnas. 151261398

Doody, R. S., Thomas, R. G., Farlow, M., Iwatsubo, T., Vellas, B., Joffe, S., et al. (2014). Phase 3 trials of solanezumab for mild-to-moderate Alzheimer's disease. N. Engl. J. Med. 370, 311-321. doi: 10.1056/NEJMoa1312889

Fan, S., Zheng, Y., Liu, X., Fang, W., Chen, X., Liao, W., et al. (2018). Curcuminloaded PLGA-PEG nanoparticles conjugated with B6 peptide for potential use in Alzheimer's disease. Drug Deliv. 25, 1091-1102. doi: 10.1080/10717544.2018. 1461955

Formicola, B., Cox, A., Dal Magro, R., Masserini, M., and Re, F. (2019). Nanomedicine for the treatment of Alzheimer's disease. J. Biomed. Nanotechnol. 15, 1997-2024. doi: 10.1166/jbn.2019.2837

Gong, Z., Chen, D., Xie, F., Liu, J., Zhang, H., Zou, H., et al. (2016). Codelivery of salinomycin and doxorubicin using nanoliposomes for targeting both liver cancer cells and cancer stem cells. Nanomedicine 11, 2565-2579. doi: 10.2217/nnm-2016-0137

Haass, C., and Selkoe, D. J. (2007). Soluble protein oligomers in neurodegeneration: lessons from the Alzheimer's amyloid $\beta$-peptide. Nat. Rev. Mol. Cell Biol. 8, 101-112. doi: 10.1038/nrm2101

Hampel, H., Toschi, N., Babiloni, C., Baldacci, F., Black, K. L., Bokde, A. L. W., et al. (2018). Revolution of Alzheimer precision neurology: passageway of systems biology and neurophysiology. J. Alzheimers Dis. 64, S47-S105. doi: 10.3233/JAD-179932

Hardy, J., and Selkoe, D. J. (2002). The amyloid hypothesis of Alzheimer's disease: progress and problems on the road to therapeutics. Science 297, 353-356. doi: 10.1126/science.1072994

Hasegawa, T., Mikoda, N., Kitazawa, M., and LaFerla, F. M. (2010). Treatment of Alzheimer's disease with anti-homocysteic acid antibody in 3xTg-AD male mice. PLoS One 5:e8593. doi: 10.1371/journal.pone.0008593

Henderson, S. J., Andersson, C., Narwal, R., Janson, J., Goldschmidt, T. J., Appelkvist, P., et al. (2014). Sustained peripheral depletion of amyloid- $\beta$ with a novel form of neprilysin does not affect central levels of amyloid- $\beta$. Brain 137, 553-564. doi: 10.1093/brain/awt308

Hernandez, F., and Avila, J. (2008). Tau aggregates and tau pathology. J. Alzheimers Dis. 14, 449-452. doi: 10.3233/jad-2008-14414

Iwatsubo, T., Odaka, A., Suzuki, N., Mizusawa, H., Nukina, N., and Ihara, Y. (1994). Visualization of $A \beta 42(43)$ and $A \beta 40$ in senile plaques with end-specific $\mathrm{A} \beta$ monoclonals: evidence that an initially deposited species is $\mathrm{A} \beta 42(43)$. Neuron 13, 45-53. doi: 10.1016/0896-6273(94)90458-8

Janus, C. (2003). Vaccines for Alzheimer's disease: how close are we? CNS Drugs 17, 457-474. doi: 10.2165/00023210-200317070-00001

Karthivashan, G., Ganesan, P., Park, S. Y., Kim, J. S., and Choi, D. K. (2018). Therapeutic strategies and nano-drug delivery applications in management of ageing Alzheimer's disease. Drug Deliv. 25, 307-320. doi: 10.1080/10717544. 2018.1428243 
Kim, D. S., Park, S. Y., and Kim, J. K. (2001). Curcuminoids from Curcuma longa L. (Zingiberaceae) that protect PC12 rat pheochromocytoma and normal human umbilical vein endothelial cells from $\beta A(1-42)$ insult. Neurosci. Lett. 303, 57-61. doi: 10.1016/s0304-3940(01)01677-9

Klajnert, B., Wasiak, T., Ionov, M., Fernandez-Villamarin, M., Sousa-Herves, A., Correa, J., et al. (2012). Dendrimers reduce toxicity of A $\beta$ 1-28 peptide during aggregation and accelerate fibril formation. Nanomedicine 8, 1372-1378. doi: 10.1016/j.nano.2012.03.005

Kontsekova, E., Zilka, N., Kovacech, B., Novak, P., and Novak, M. (2014). First-in-man tau vaccine targeting structural determinants essential for pathological tau-tau interaction reduces tau oligomerisation and neurofibrillary degeneration in an Alzheimer's disease model. Alzheimers Res. Ther. 6:44. doi: 10.1186/alzrt278

Lemere, C. A. (2013). Immunotherapy for Alzheimer's disease: hoops and hurdles. Mol. Neurodegener. 8:36. doi: 10.1186/1750-1326-8-36

Lemere, C. A., Maier, M., Jiang, L., Peng, Y., and Seabrook, T. J. (2006). Amyloid- $\beta$ immunotherapy for the prevention and treatment of Alzheimer disease: lessons from mice, monkeys, and humans. Rejuvenation Res. 9, 77-84. doi: 10.1089/rej. 2006.9.77

Lemere, C. A., Spooner, E. T., LaFrancois, J., Malester, B., Mori, C., Leverone, J. F., et al. (2003). Evidence for peripheral clearance of cerebral A $\beta$ protein following chronic, active A $\beta$ immunization in PSAPP mice. Neurobiol. Dis. 14, 10-18. doi: 10.1016/s0969-9961(03)00044-5

Liu, Y., An, S., Li, J., Kuang, Y., He, X., Guo, Y., et al. (2016). Brain-targeted co-delivery of therapeutic gene and peptide by multifunctional nanoparticles in Alzheimer's disease mice. Biomaterials 80, 33-45. doi: 10.1016/j.biomaterials. 2015.11.060

Logovinsky, V., Satlin, A., Lai, R., Swanson, C., Kaplow, J., Osswald, G., et al. (2016). Safety and tolerability of BAN2401-a clinical study in Alzheimer's disease with a protofibril selective $\mathrm{A} \beta$ antibody. Alzheimers Res. Ther. 8:14. doi: 10.1186/s13195-016-0181-2

Mancini, S., Balducci, C., Micotti, E., Tolomeo, D., Forloni, G., Masserini, M., et al. (2017). Multifunctional liposomes delay phenotype progression and prevent memory impairment in a presymptomatic stage mouse model of Alzheimer disease. J. Control. Release 258, 121-129. doi: 10.1016/j.jconrel.2017.05.013

Mancini, S., Minniti, S., Gregori, M., Sancini, G., Cagnotto, A., Couraud, P. O., et al. (2016). The hunt for brain A $\beta$ oligomers by peripherally circulating multifunctional nanoparticles: potential therapeutic approach for Alzheimer disease. Nanomedicine 12, 43-52. doi: 10.1016/j.nano.2015.09.003

Mangialasche, F., Solomon, A., Winblad, B., Mecocci, P., and Kivipelto, M. (2010). Alzheimer's disease: clinical trials and drug development. Lancet Neurol. 9, 702-716. doi: 10.1016/S1474-4422(10)70119-8

Markoutsa, E., Papadia, K., Clemente, C., Flores, O., and Antimisiaris, S. G. (2012). Anti-A $\beta-M A b$ and dually decorated nanoliposomes: effect of $A \beta 1-42$ peptides on interaction with hCMEC/D3 cells. Eur. J. Pharm. Biopharm. 81, 49-56. doi: 10.1016/j.ejpb.2012.02.006

Matsuoka, Y., Saito, M., LaFrancois, J., Saito, M., Gaynor, K., Olm, V., et al. (2003). Novel therapeutic approach for the treatment of Alzheimer's disease by peripheral administration of agents with an affinity to $\beta$-amyloid. J. Neurosci. 23, 29-33. doi: 10.1523/JNEUROSCI.23-01-00029.2003

Monk, B. J., Herzog, T. J., Wang, G., Triantos, S., Maul, S., Knoblauch, R., et al. (2020). A phase 3 randomized, open-label, multicenter trial for safety and efficacy of combined trabectedin and pegylated liposomal doxorubicin therapy for recurrent ovarian cancer. Gynecol. Oncol. 156, 535-544. doi: 10.1016/j. ygyno.2019.12.043

Morgan, D. (2006). Immunotherapy for Alzheimer's disease. J. Alzheimers Dis. 9, 425-432. doi: 10.3233/jad-2006-9s348

Morgan, D. (2011). Immunotherapy for Alzheimer's disease. J. Intern. Med. 269, 54-63. doi: 10.1111/j.1365-2796.2010.02315.x

Mori, T., Maeda, J., Shimada, H., Higuchi, M., Shinotoh, H., Ueno, S., et al. (2012). Molecular imaging of dementia. Psychogeriatrics 12, 106-114. doi: 10.1111/j. 1479-8301.2012.00409.x

Mourtas, S., Canovi, M., Zona, C., Aurilia, D., Niarakis, A., La Ferla, B., et al. (2011). Curcumin-decorated nanoliposomes with very high affinity for amyloid- $\beta 1-42$ peptide. Biomaterials 32, 1635-1645. doi: 10.1016/j. biomaterials.2010.10.027

Novak, P., Kontsekova, E., Zilka, N., and Novak, M. (2018a). Ten years of tau-targeted immunotherapy: the path walked and the roads ahead. Front. Neurosci. 12:798. doi: 10.3389/fnins.2018.00798
Novak, P., Schmidt, R., Kontsekova, E., Kovacech, B., Smolek, T., Katina, S., et al. (2018b). FUNDAMANT: an interventional 72-week phase 1 follow-up study of AADvac1, an active immunotherapy against tau protein pathology in Alzheimer's disease. Alzheimers Res. Ther. 10:108. doi: 10.1186/s13195-0180436-1

Olsson, F., Schmidt, S., Althoff, V., Munter, L. M., Jin, S., Rosqvist, S., et al. (2014). Characterization of intermediate steps in amyloid $\beta(\mathrm{A} \beta)$ production under near-native conditions. J. Biol. Chem. 289, 1540-1550. doi: 10.1074/jbc.m113. 498246

Ordóñez-Gutiérrez, L., Posado-Fernández, A., Ahmadvand, D., Lettiero, B., Wu, L., Antón, M., et al. (2017). ImmunoPEGliposome-mediated reduction of blood and brain amyloid levels in a mouse model of Alzheimer's disease is restricted to aged animals. Biomaterials 112, 141-152. doi: 10.1016/j. biomaterials.2016.07.027

Ordóñez-Gutiérrez, L., Re, F., Bereczki, E., Ioja, E., Gregori, M., Andersen, A. J., et al. (2015). Repeated intraperitoneal injections of liposomes containing phosphatidic acid and cardiolipin reduce amyloid- $\beta$ levels in APP/PS1 transgenic mice. Nanomedicine 11, 421-430. doi: 10.1016/j.nano. 2014.09.015

Orgogozo, J. M., Gilman, S., Dartigues, J. F., Laurent, B., Puel, M., Kirby, L. C., et al. (2003). Subacute meningoencephalitis in a subset of patients with AD after A 442 immunization. Neurology 61, 46-54. doi: 10.1212/01.wnl.0000073623. 84147.a8

Panza, F., Logroscino, G., Imbimbo, B. P., and Solfrizzi, V. (2014). Is there still any hope for amyloid-based immunotherapy for Alzheimer's disease? Curr. Opin. Psychiatry 27, 128-137. doi: 10.1097/yco.0000000000000041

Panza, F., Lozupone, M., Seripa, D., and Imbimbo, B. P. (2019). Amyloid- $\beta$ immunotherapy for Alzheimer disease: is it now a long shot? Ann. Neurol. 85, 303-315. doi: 10.1002/ana.25410

Poirier, Y., Grimm, A., Schmitt, K., and Eckert, A. (2019). Link between the unfolded protein response and dysregulation of mitochondrial bioenergetics in Alzheimer's disease. Cell. Mol. Life Sci. 76, 1419-1431. doi: 10.1007/s00018019-03009-4

Pride, M., Seubert, P., Grundman, M., Hagen, M., Eldridge, J., and Black, R. S. (2008). Progress in the active immunotherapeutic approach to Alzheimer's disease: clinical investigations into AN1792-associated meningoencephalitis. Neurodegener. Dis. 5, 194-196. doi: 10.1159/000113700

Rakover, I., Arbel, M., and Solomon, B. (2007). Immunotherapy against APP $\beta$-secretase cleavage site improves cognitive function and reduces neuroinflammation in Tg2576 mice without a significant effect on brain A $\beta$ levels. Neurodegener. Dis. 4, 392-402. doi: 10.1159/000103250

Salloway, S., Sperling, R., and Brashear, H. R. (2014a). Phase 3 trials of solanezumab and bapineuzumab for Alzheimer's disease. N. Engl. J. Med. 370:1460. doi: 10.1056/nejmc1402193

Salloway, S., Sperling, R., Fox, N. C., Blennow, K., Klunk, W., Raskind, M. M., et al. (2014b). Two phase 3 trials of bapineuzumab in mild-to-moderate Alzheimer's disease. N. Engl. J. Med. 370, 322-333. doi: 10.1056/NEJMoa 1304839

Sanchez-Lopez, E., Ettcheto, M., Egea, M. A., Espina, M., Calpena, A. C., Folch, J., et al. (2017). New potential strategies for Alzheimer's disease prevention: pegylated biodegradable dexibuprofen nanospheres administration to APPswe/PS1dE9. Nanomedicine 13, 1171-1182. doi: 10.1016/j.nano.2016. 12.003

Schenk, D., Barbour, R., Dunn, W., Gordon, G., Grajeda, H., Guido, T., et al. (1999). Immunization with amyloid- $\beta$ attenuates Alzheimer-diseaselike pathology in the PDAPP mouse. Nature 400, 173-177. doi: 10.1038/ 22124

Schneider, L. S., Mangialasche, F., Andreasen, N., Feldman, H., Giacobini, E., Jones, R., et al. (2014). Clinical trials and late-stage drug development for Alzheimer's disease: an appraisal from 1984 to 2014. J. Intern. Med. 275, 251-283. doi: 10.1111/joim.12191

Selkoe, D. J. (2001). Alzheimer's disease results from the cerebral accumulation and cytotoxicity of amyloid $\beta$-protein. J. Alzheimers Dis. 3, 75-80. doi: 10.3233/ jad-2001-3111

Selkoe, D. J., and Hardy, J. (2016). The amyloid hypothesis of Alzheimer's disease at 25 years. EMBO Mol. Med. 8, 595-608. doi: 10.15252/emmm. 201606210

Sevigny, J., Chiao, P., Bussière, T., Weinreb, P. H., Williams, L., Maier, M., et al. (2016). The antibody aducanumab reduces $A \beta$ plaques in Alzheimer's disease. Nature 537, 50-50. doi: 10.1038/nature19323 
Shi, J., Su, Y., Liu, W., Chang, J., and Zhang, Z. (2017). A nanoliposomebased photoactivable drug delivery system for enhanced cancer therapy and overcoming treatment resistance. Int. J. Nanomedicine 12, 8257-8275. doi: 10.2147/IJN.S143776

Sigurdsson, E. M. (2008). Immunotherapy targeting pathological tau protein in Alzheimer's disease and related tauopathies. J. Alzheimers Dis. 15, 157-168. doi: 10.3233/jad-2008-15202

Sigurdsson, E. M. (2014). Tau immunotherapy and imaging. Neurodegener. Dis. 13, 103-106. doi: 10.1159/000354491

Sigurdsson, E. M. (2016). Tau immunotherapy. Neurodegener. Dis. 16, 34-38. doi: $10.1159 / 000440842$

Sigurdsson, E. M. (2018). Tau immunotherapies for Alzheimer's disease and related tauopathies: progress and potential pitfalls. J. Alzheimers Dis. 64, S555-s565. doi: 10.3233/JAD-179937

Singh, M., Thakur, V., Deshmukh, R., Sharma, A., Rathore, M. S., Kumar, A., et al. (2018). Development and characterization of morin hydrate-loaded micellar nanocarriers for the effective management of Alzheimer's disease. J. Microencapsul. 35, 137-148. doi: 10.1080/02652048.2018. 1441916

Solomon, B., Koppel, R., Frankel, D., and Hanan-Aharon, E. (1997). Disaggregation of Alzheimer $\beta$-amyloid by site-directed mAb. Proc. Natl. Acad. Sci. U S A 94, 4109-4112. doi: 10.1073/pnas.94.8.4109

Song, H., Wei, M., Zhang, N., Li, H., Tan, X., Zhang, Y., et al. (2018). Enhanced permeability of blood-brain barrier and targeting function of brain via borneol-modified chemically solid lipid nanoparticle. Int. J. Nanomedicine 13, 1869-1879. doi: 10.2147/ijn.s161237

Su, X., Song, H., Niu, F., Yang, K., Kou, G., Wang, X., et al. (2015). Codelivery of doxorubicin and PEGylated C16-ceramide by nanoliposomes for enhanced therapy against multidrug resistance. Nanomedicine 10, 2033-2050. doi: $10.2217 / \mathrm{nnm} .15 .50$

Sutcliffe, J. G., Hedlund, P. B., Thomas, E. A., Bloom, F. E., and Hilbush, B. S. (2011). Peripheral reduction of $\beta$-amyloid is sufficient to reduce brain $\beta$ amyloid: implications for Alzheimer's disease. J. Neurosci. Res. 89, 808-814. doi: $10.1002 /$ jnr.22603

Tayeb, H. O., Yang, H. D., Price, B. H., and Tarazi, F. I. (2012). Pharmacotherapies for Alzheimer's disease: beyond cholinesterase inhibitors. Pharmacol. Ther. 134, 8-25. doi: 10.1016/j.pharmthera.2011.12.002

Theunis, C., Crespo-Biel, N., Gafner, V., Pihlgren, M., López-Deber, M. P., Reis, P., et al. (2013). Efficacy and safety of a liposome-based vaccine against protein Tau, assessed in tau.P301L mice that model tauopathy. PLoS One 8:e72301. doi: 10.1371/journal.pone.0072301

Vieira, D. B., and Gamarra, L. F. (2016). Getting into the brain: liposome-based strategies for effective drug delivery across the bloodbrain barrier. Int. J. Nanomedicine 11, 5381-5414. doi: 10.2147/ijn. s117210
Wisniewski, T., and Frangione, B. (2005). Immunological and anti-chaperone therapeutic approaches for Alzheimer disease. Brain Pathol. 15, 72-77. doi: 10.1111/j.1750-3639.2005.tb00102.x

Wisniewski, T., and Goñi, F. (2014). Immunotherapy for Alzheimer's disease. Biochem. Pharmacol. 88, 499-507. doi: 10.1016/j.bcp.2013.12.020

Wisniewski, T., and Goñi, F. (2015). Immunotherapeutic approaches for Alzheimer's disease. Neuron 85, 1162-1176. doi: 10.1016/j.neuron.2014.12.064

Wong, K. H., Riaz, M. K., Xie, Y., Zhang, X., Liu, Q., Chen, H., et al. (2019). Review of current strategies for delivering Alzheimer's disease drugs across the bloodbrain barrier. Int. J. Mol. Sci. 20:E381. doi: 10.3390/ijms20020381

Wu, K., Su, D., Liu, J., Saha, R., and Wang, JP. (2019). Magnetic nanoparticles in nanomedicine: a review of recent advances. Nanotechnology 30:502003. doi: 10.1088/1361-6528/ab4241

Yang, F., Lim, G. P., Begum, A. N., Ubeda, O. J., Simmons, M. R., Ambegaokar, S. S., et al. (2005). Curcumin inhibits formation of amyloid $\beta$ oligomers and fibrils, binds plaques, and reduces amyloid in vivo. J. Biol. Chem. 280, 5892-5901. doi: 10.1074/jbc.m404751200

Yoshiyama, Y., Lee, V. M., and Trojanowski, J. Q. (2013). Therapeutic strategies for tau mediated neurodegeneration. J. Neurol. Neurosurg. Psychiatry 84, 784-795. doi: 10.1136/jnnp-2012-303144

Yuyama, K., and Igarashi, Y. (2017). Exosomes as carriers of Alzheimer's amyloidB. Front. Neurosci. 11:229. doi: 10.3389/fnins.2017.00229

Zhang, L., Fiala, M., Cashman, J., Sayre, J., Espinosa, A., Mahanian, M., et al. (2006). Curcuminoids enhance amyloid- $\beta$ uptake by macrophages of Alzheimer's disease patients. J. Alzheimers Dis. 10, 1-7. doi: 10.3233/jad-200610101

Zhang, X., Huai, Y., Cai, J., Song, C., and Zhang, Y. (2019). Novel antibody against oligomeric amyloid- $\beta$ : insight into factors for effectively reducing the aggregation and cytotoxicity of amyloid- $\beta$ aggregates. Int. Immunopharmacol. 67, 176-185. doi: 10.1016/j.intimp.2018.12.014

Zhao, J., Nussinov, R., and Ma, B. (2017). Mechanisms of recognition of amyloid- $\beta$ (A $\beta$ ) monomer, oligomer, and fibril by homologous antibodies. J. Biol. Chem. 292, 18325-18343. doi: 10.1074/jbc.M117.801514

Conflict of Interest: The authors declare that the research was conducted in the absence of any commercial or financial relationships that could be construed as a potential conflict of interest.

Copyright (C) 2020 Ordónez-Gutiérrez and Wandosell. This is an open-access article distributed under the terms of the Creative Commons Attribution License (CC BY). The use, distribution or reproduction in other forums is permitted, provided the original author(s) and the copyright owner(s) are credited and that the original publication in this journal is cited, in accordance with accepted academic practice. No use, distribution or reproduction is permitted which does not comply with these terms. 